\title{
New knowledge of the pathogenesis of gout
}

\author{
J. T. SCOTT \\ From Charing Cross Hospital and the Kennedy Institute of Rheumatology, London
}

The clinical features of gout have been well-recognised since ancient times. Knowledge of its underlying metabolic causes began towards the end of the eighteenth century with the discovery of uric acid in urinary calculi and gouty tophi, and during the nineteenth century Sir Alfred Garrod showed that the blood of gouty subjects contained an excess of uric acid which became deposited in crystalline form in the joints. The later work of Emil Fischer, establishing that uric acid was a purine compound and thus potentially related to the nucleic acid constituents adenine and guanine, and the improved methodology of uric acid determination by Folin and Dennis completed this part of the story.

Other developments during the twentieth century have included, firstly, the realisation that hyperuricaemia and gout have many different causes; secondly, a swift advance, gained by biochemical, isotope, and cell-culture techniques, in our knowledge of purine metabolism, including the discovery by Seegmiller and his colleagues in 1967 of the first specific enzymatic defect (HGPRT deficiency) responsible for one special type of gout; and, thirdly, from the therapeutic aspect, a remarkable facility to control both the acute gouty attack and the level of uric acid in the blood.

People who develop gout have usually lived for many years, unknown to themselves, with a raised plasma level of uric acid (asymptomatic hyperuricaemia), until eventually crystals of sodium urate precipitated in a joint provoke a sudden tissue reaction which leads to the first attack of acute gouty arthritis. Acute attacks each last for only short periods. They are followed by intervals of widely varying duration of complete freedom from symptoms (intercritical gout). Nevertheless, hyperuricaemia persists. In time, in some untreated individuals, joints may no longer return to their normal state; deposits of urate (tophi) form around the joints and elsewhere, and the patient enters the stage of chronic tophaceous gouty arthritis.

The phases in the pathogenesis of gout therefore consist of (1) hyperuricaemia with an increased total uric acid pool; (2) deposition of urate crystals; and (3) an inflammatory response leading to gouty arthritis. This paper outlines our present ideas about these three phases.

\section{Hyperuricaemia and gout}

Less than 30 years ago gout and hyperuricaemia were regarded as a single entity following 'a Mendelian dominant pattern of inheritance with incomplete penetrance' (Stecher et al., 1949). This unifactorial concept, however, soon became outmoded as it was realised that numerous influences could bear upon uric acid formation and excretion.

Uric acid (2,6.8-trioxypurine) is the end-product of purine metabolism in man and the higher primates, who, late in the course of evolution, have lost the enzyme uricase. Purines are derived either preformed from the diet or from tissue nucleic acids or from de novo biosynthesis, a complex system of enzymatic conversion controlling their synthesis and catabolism. Disposal of uric acid is mainly through the kidney and to a lesser extent into the gastrointestinal tract. Most uric acid in the plasma is freely filterable at the glomerulus. A large part of the filtrate is reabsorbed in the proximal renal tubule, the urinary urate being largely derived from further active tubular secretion. Although tubular transport of urate is almost certainly bidirectional, details of its components remain to be clarified.

\section{FACTORS CAUSING HYPERURICAEMIA}

The plasma concentration of uric acid can be raised by a number of inborn or environmental factors acting either alone or in combination. They are associated with an increased rate of formation or a decreased rate of excretion. There are also other factors associated with hyperuricaemia and gout of which the exact mechanism remains uncertain.

\section{Increased formation of uric acid}

Factors that increase uric acid formation are: (1) specific enzyme abnormalities such as decreased activity of hypoxanthine-guanine phosphoribosyltransferase, increased activity of phosphoribosyl- 
pyrophosphate synthetase, deficiency of glucose-6phosphatase, increased activity of glutathione reductase; (2) increased turnover of nucleoprotein; (3) diet; and (4) exogenous chemicals.

\section{Decreased excretion of uric acid}

Factors that decrease uric acid excretion are: (1) alterations in renal function and contraction of extracellular fluid volume; (2) drugs; (3) lactic acidaemia; (4) starvation and ketosis; (5) essential hypertension; (6) lead poisoning; (7) hypercalcaemia; and (8) myxoedema.

\section{Other factors}

Other factors that cause hyperuricaemia are: (1) race, sex, and age; (2) genetic factors; (3) body weight; (4) social class and intelligence; (5) alcohol; (6) cardiovascular disease; (7) diabetes; and (8) haemoglobin and plasma proteins.

The complex problems of uric acid formation and excretion and numerous factors that can influence them are reviewed in detail elsewhere (Wyngaarden and Kelley, 1976; Scott, 1978).

\section{PRIMARY AND SECONDARY GOUT}

The concept of primary and secondary gout was developed by Talbott (1959). The term 'primary gout' implies that the cause of hyperuricaemia is attributable to an inherent metabolic abnormality, occasionally identifiable (for example HGPRT deficiency) but nearly always unknown. 'Secondary gout' has signified a situation where there is an identifiable and usually acquired cause. Originally it was applied to proliferative haemopoietic disorders such as polycythaemia rubra vera where the excess of uric acid was caused by tissue breakdown of nucleic acids. Later it was extended to include circumstances when hyperuricaemia is due to a definable renal factor.

In nearly all patients with primary gout as seen in our clinics the increased body content of uric acid is probably due to a combination of different mechanisms. Overproduction of uric acid is found in some, the exact proportion depending on patient selection and on the methods used to detect overproduction-for example, excretion on a lowpurine diet or more sensitive techniques such as the incorporation of isotopic precursors into uric acid. Overproduction is certainly not the sole cause of hyperuricaemia in over $25 \%$ of gout patients, and the figure is probably considerably smaller than this. The part played by impaired excretion in primary gout has been controversial. Overall, clearance of urate is impaired in patients with gout compared with normal people. In a series of cases in this country a mean urate clearance of 5.8 $\mathrm{ml} / \mathrm{min}$ was found in normal subjects compared with $3.6 \mathrm{ml} / \mathrm{min}$ in gout patients (Snaith and Scott, 1971). To these quantitative variations in genetically determined metabolic and renal functions, the precise nature of which has yet to be elucidated, are added in many cases the effects of external agents, particularly food (with regard to both its purine and energy content), drugs (for example, diuretics), and alcoholic liquors. As Acheson and Chan (1969) stated, 'The associates of a high uric acid are the associates of plenty'.

\section{Mechanism of urate crystal formation}

SUPERSATURATION OF SERUM OR SYNOVIAL FLUID WITH MONOSODIUM URATE

Aqueous solutions having the sodium content of serum $(136 \mathrm{mmol} / \mathrm{l})$ are saturated with urate at $384 \mu \mathrm{mol} / 1(6.4 \mathrm{mg} / 100 \mathrm{ml})$ at $37^{\circ} \mathrm{C}$. Solubility in plasma is rather greater, perhaps because of the presence of urate-binding proteins and other solubilising low molecular weight compounds, so that saturation of monosodium urate in human plasma occurs at concentrations of about $420 \mu \mathrm{mol} / 1$ $(7 \mathrm{mg} / 100 \mathrm{ml})$. Considerably higher concentrations can be achieved in supersaturated solutions. The mean serum uric acid level for men in the United Kingdom is $330 \mu \mathrm{mol} / \mathrm{l}(5 \cdot 5 \mathrm{mg} / 100 \mathrm{ml})$ with a standard deviation of $60 \mu \mathrm{mol} / 1(1.0 \mathrm{mg} / 100 \mathrm{ml})$, so that about $7 \%$ of the male population has a concentration of over $420 \mu \mathrm{mol} / 1$ (Sturge et al., 1977). Stable supersaturated solutions of up to $5400 \mu \mathrm{mol} / 1$ ( $90 \mathrm{mg} / 100 \mathrm{ml})$ have been observed in patients with leukaemia or lymphoma after cytotoxic therapy (Kjellstrand et al., 1974).

From clinical and epidemiological studies there is an undoubted correlation between a high serum urate concentration and the prevalance of gout and renal stones (Hall et al., 1967), but equally considerable degrees of hyperuricaemia can undoubtedly be sustained without evidence of urate deposition. For example, Fessel (1972) found that only three out of $66 \mathrm{men}$ with levels above $540 \mu \mathrm{mol} / 1(9 \mathrm{mg} / 100$ $\mathrm{ml}$ ) (in whom pre-existing gout, cardiovascular and renal disease, and diabetes has been excluded) developed gout after four years.

Not only are many people hyperuricaemic without developing gout but urate deposition, when it does occur, is selective for the connective tissues of the body (Sokoloff, 1957). Crystals are found in cartilage, tendon sheaths, synovial fluid, and subcutaneous tissue but not generally in muscle, brain, intestine, liver, or other parenchymal organs. The rare cardiac involvement is confined to the conducting system and valves. Urate deposition in renal parenchyma seems to occur in connective 
tissue, shown by Farber et al. (1962) and others to be rich in chondroitin sulphate. Intratubular deposition (urolithiasis) in acid urine is of uric acid rather than of the sodium salt. While hyperuricaemia of sufficient degree and duration may be regarded as a sine qua non for urate deposition, there are factors which determine both its occurrence in some individuals and not in others and its localisation in certain tissues. Knowledge of such factors is rudimentary. Some of the following may be important.

\section{PROTEIN BINDING OF URATE}

Urate in the blood is mainly in the free form. Binding to plasma protein was formerly considered to be negligible (Yu and Gutman 1953). Later, an affinity was demonstrated between the urate ion and both albumin and a specific $a_{1-a_{2}}$ globulin. Some patients with gout have been said to show a reduced urate binding capacity, leading perhaps to the precipitation of cyrstals at lower than usual plasma concentrations of urate. There seems, however, to be no significant difference in binding capacity between gout patients and controls (Campion et al., 1975) and the clinical significance of urate binding remains uncertain.

\section{TURNOVER OF PROTEOGLYCANS}

The possibility of altered connective tissue metabolism leading to the deposition of urate crystals in gout has been investigated by Katz (1975) and his colleagues. Favoured sites of urate deposition such as articular and other cartilages are rich in ground substance containing acid glycosaminoglycans. Intact proteoglycans enhance the solubility of urate and inhibit crystallisation. Proteoglycans from bovine nasal cartilage increase urate solubility, a feature not found with unbound chondroitin sulphate or trypsin-digested cartilage. Katz suggests that in gout there is an abnormal turnover of proteoglycans, reducing their binding capacity for urate and resulting in the deposition of crystals from supersaturated tissue fluid. In support of this hypothesis serum glycosaminoglycan concentrations in gout are said to lie at about three times control values, returning to normal after treatment with colchicine (Katz, 1977).

\section{TEMPERATURE}

The solubility of monosodium urate in the presence of physiological concentrations of sodium has been shown to fall sharply with decreasing temperaturefrom $408 \mu \mathrm{mol} / 1(6.8 \mathrm{mg} / 100 \mathrm{ml})$ at $37^{\circ} \mathrm{C}$ to 270 $\mu \mathrm{mol} / 1(4.5 \mathrm{mg} / 100 \mathrm{ml})$ at $30^{\circ} \mathrm{C}$ (Loeb, 1972). This may be relevant to the peripheral distribution of gouty arthritis, with cooling of extremity joints during nocturnal rest after exercise during the day.
Conversely, the heat associated with inflammation may limit the process by enhancing the solubility of urate crystals.

\section{TRAUMA AND EXERCISE}

Acute gouty arthritis sometimes follows trauma or exercise, particularly in the first metatarsophalangeal joint of the great toe. Conceivably mechanical damage to cartilage predisposes to crystal deposition or desquamation of crystals from an articular crust sets off an attack. The severity of experimental urate arthritis in dogs is enhanced by exercise (Agudelo et al., 1972)-a further experimental observation with clinical implications.

ALTERED HYDROGEN ION CONCENTRATION Seegmiller et al. (1963) suggested that increased metabolic activity in synovial leucocytes during phagocytosis of urate crystals leads to increased lactic acid production, a fall in $\mathrm{pH}$, and further precipitation of urate. But the deposit is not of uric acid but of monosodium urate, which is more soluble at $\mathrm{pH} 6.0$ or 6.5 than at $\mathrm{pH} 7 \cdot 4$. So $\mathrm{pH}$ changes are unlikely to be significant in the pathogenesis of gouty arthritis-at least so far as crystallisation is concerned.

\section{RESORPTION OF EXTRACELLULAR FLUID}

Urate solubility is increased by a number of factors, including the presence of albumin. Lack of interstital fluid albumin may therefore predispose to urate precipitation (Kippen et al., 1974). Simkin (1973) showed that urate concentration rises in resolving effusions, and suggested that the resolution of small traumatic effusions in the metatarsophalangeal joints and elsewhere predisposes to crystal deposition.

\section{AGEING AND AVASCULARITY}

Age-related changes in connective tissue and reduction in blood flow may influence the rate of dispersal of a local increase in urate concentration and hence provoke the formation of crystals.

\section{Mechanism of inflammatory response}

Several factors may operate in a greater or lesser degree to produce the gouty inflammatory response (Kellermeyer and Naff, 1975; Wyngaarden and Kelley 1976).

\section{URATE CRYSTALS}

Modern views support the proposition by Garrod (1859) that 'The deposited urate of soda may be looked upon as the cause, and not the effect, of the gouty inflammation'. The association of crystalline 
monosodium urate with acute gout is now clearly established. Urate can be demonstrated within synovial tissue during an attack (Sokoloff, 1957) and examination of joint fluid for urate crystals (McCarty and Hollander, 1961) has become a routine diagnostic measure. The crystals can be seen by polarised light as negatively birefringent needles often lying within polymorphs. It seems evident that urate crystals initiate the gouty attack. The injection of crystalline particles of appropriate size and shape - not only urate but also oxalate and other substances-can produce an inflammatory response in the skin, subcutaneous tissues, and joints of man and animals (Faires and McCarty, 1962; Seegmiller et al., 1962). A similar mechanism no doubt operates in the form of crystal-induced synovitis that is a feature of chondrocalcinosis, in which acute joint inflammation is a response to crystals of calcium pyrophosphate dihydrate.

\section{POLYMORPHONUCLEAR LEUCOCYTES}

Urate-induced inflammation appears to depend largely on the presence of polymorphonuclear leucocytes. These are the characteristic cells of gouty synovial effusions and can often be seen to contain urate crystals (Fig. 1). Whereas crystals injected

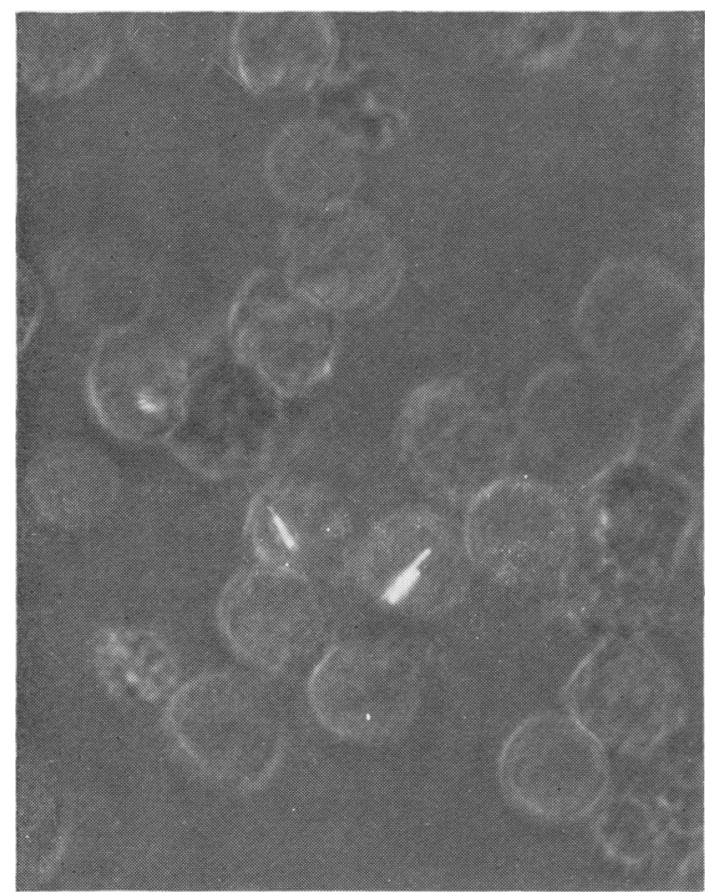

Fig. 1 Intracellular crystals of monosodium urate from joint fluid viewed under polarised light. $(\times 700)$ into the joints of normal dogs induce an inflammatory response they fail to do so in dogs made leucopenic with vancomycin or antipolymorph serum. Responsiveness is restored by the replacement of leucocytes (Phelps and McCarty, 1966; Chang and Gralla, 1968). Schumacher et al. (1974) have observed the course of events after the injection of crystals: there is an uptake of crystals by synovial lining cells and other mononuclear cells; vasodilation; polymorph margination; rising intra-articular pressure; chemotaxis; and the accumulation of polymorphs in synovial fluid with phagocytosis of crystals. Leucocytes appear to release a factor chemotactic for other leucocytes, a process inhibited by colchicine (Phelps, 1970). This is unlikely to be specific for crystals but may be an important mechanism for attracting more polymorphs into the joint space.

Acute gouty arthritis, however, occurred in the absence of synovial fiuid leucocytes (Ortel and Newcombe, 1974), suggesting that phagocytic cells in the synovial membrane may carry out a similar function. Also crystals of monosodium urate can activate human platelets-an initial secretory phase with active release of serotonin, ATP, and ADP is followed by lysis involving slower loss of all platelet constituents (Ginsberg et al., 1977). Such interactions may again contribute to gouty inflammation.

\section{MEMBRANOLYSIS}

Shortly after ingestion urate crystals can be seen to be surrounded by a closely applied phagosome membrane (Schumacher and Phelps, 1971). This appears to be followed by fusion with lysosomes to produce enzyme-containing phagolysosomes; digestion of the protein coat on the crystal; direct interaction of urate crystal with lysosome, perhaps by hydrogen bonding to its membrane which is rich in cholesterol and testosterone; perforation; cell injury; the escape of lysosomal enzymes; and subsequent inflammation (Wallingford and McCarty, 1971; Weissmann and Rita, 1972).

\section{HAGEMAN FACTOR: KALLIKREIN-KININ SYSTEM}

Urate crystals, like other negatively-charged surfaces, are capable of activating the Hageman factor of synovial fluid, leading in turn to the production of permeability-enhancing factor, kallikrein, and kinins. The concentration of kinin-like peptides in synovial fluid is very high during crystal-induced synovitis and spontaneous attacks of gout. This sequence of events is not specific for gouty synovitis. It occurs, for example, in rheumatoid arthritis. Moreover, it does not seem to be a necessary pathway, since 
monosodium urate crystals can induce an acute synovitis in chickens. Chickens lack Hageman factor and have no kinin activity in their synovial fluid (Spilberg, 1974).

\section{COMPLEMENT SYSTEM}

Natt and Byers (1973) reported that the incubation of normal human serum and urate crystals led to activation of complement. Activation depends on the concentration of urate crystals and the incubation time and temperature, with depletion of $\mathrm{C} 4, \mathrm{C} 2, \mathrm{C} 3$, and $\mathrm{C} 5$ but with minimal depletion of $\mathrm{Cl}$ and no fall in properdin activity. Heating the crystals to $200^{\circ} \mathrm{C}$ for 2 hours greatly decreases their complementinactivating properties, though not their inflammatory characteristics. Reports on complement levels in synovial fluid taken from patients with acute gout are discrepant. Some (Pekin and Zwaifler, 1964; Fostiropoulos et al., 1965) report normal levels, others (Townes and Sowa, 1970) claim a reduction. Again, it is stated that injection of purified cobra venom into dogs, depleting them of C3 and C5, reduces the intensity of urate-induced arthritis (Kellermeyer and Naff, 1975). The leucocyte response to crystals is unaffected (Spilberg and Osterland, 1970). Therefore possibly complement plays a part in crystal-induced synovitis but not an essential one.

Immunoglobulin and $\mathrm{C} 3$ have been reported to be present in the interstitial tissue of tophi and on the surface of monosodium urate crystals (Hasselbacher and Schumacher, 1976). Our own preliminary observations (with Professor John Sloper and Dr David Woodrow) on synovial membrane in four gouty synovial membranes have shown little consistency either between the cases (Table) or in the site of deposition-lining layer, plasma cells, blood vessels, interstitial tissue-so that the significance of such deposition is at present highly questionable.

\section{PROSTAGLANDINS}

Any part played by the prostaglandins is conjectural, although they have been implicated in the inflammation induced by urate crystals in the dog knee joint (Rosenthale et al., 1972), and it may be relevant that most of the drugs which are effective in terminating acute gouty arthritis, particularly indomethacin, are potent inhibitors of prostaglandin synthetase.

\section{ENDOTOXINS}

The provocation of acute gout by infection or by the intravenous injection of bacterial pyrogen (Sicuteri 1968) led Van Arman et al. (1974) to examine the effect of injecting into the joints of
Table Immunoglobulin deposition in gout synovial membrane

\begin{tabular}{llllll}
\hline Case No. & Fibrinogen & IgA & IgG & IgM & C3 \\
\hline 1 & + & \pm & + & 0 & 0 \\
2 & + & 0 & 0 & 0 & 0 \\
3 & + & + & + & 0 & \pm \\
4 & + & 0 & 0 & \pm & 0 \\
\hline
\end{tabular}

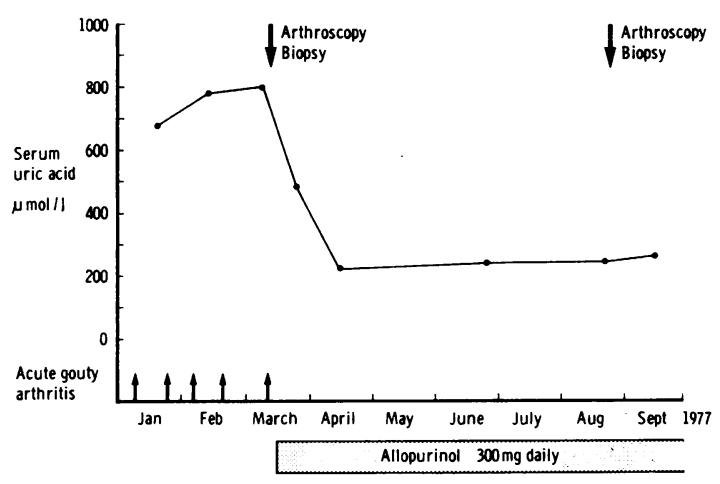

Fig. 2 Patient with acute gouty arthritis treated with allopurinol (see also Figs 3 and 4).

Conversion: SI to Traditional Units-Uric acid: $1 \mu \mathrm{mol} / \mathrm{l} \approx 0.02 \mathrm{mg} / 100 \mathrm{ml}$.

dogs urate crystals on to the surface of which had been absorbed endotoxin obtained from Escherichia coli. Such crystals produced a more severe synovitis than crystals free of endotoxin. Urate crystals injected in quantities insufficient to cause synovitis did so when endotoxin was given by mouth. These studies are unconfirmed but they illustrate the possible role of agents additional to the urate itself in contributing to the gouty attack.

\section{Conclusion}

It is thus possible to build up a concept of various factors that may be operative in the pathogenesis of gouty arthritis. Although complex interrelationships and pathways may be at work there is one piece of pharmacological evidence which suggests that gouty inflammation may be a rather more straightforward matter than that occurring in some other forms of synovitis-for example, rheumatoid arthritis. There are a number of non-steroidal anti-inflammatory agents-phenylbutazone, indomethacin, naproxen, and others-the effect of which on rheumatoid inflammation is extremely variable between different individuals. These compounds, however, have a highly predictable and repro- 


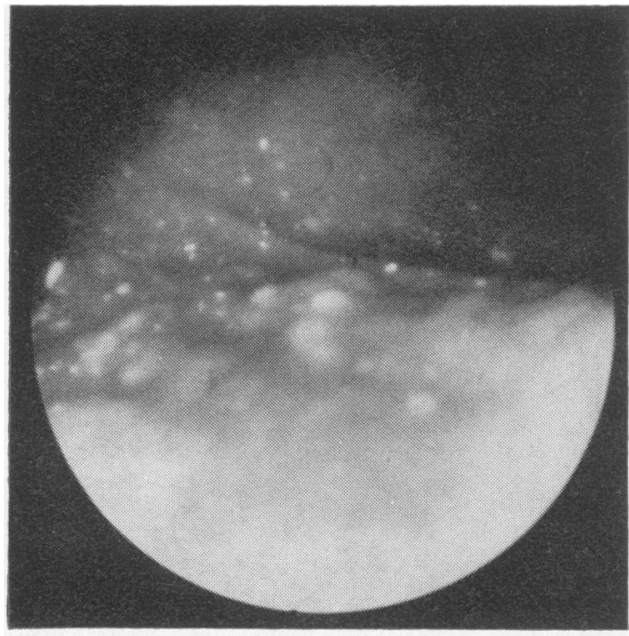

a

Fig. 3 Same patient as in Fig. 2. (a) Arthroscopic appearance March 1977 showing urate deposition on synovial membrane. (b) Synovial biopsy March 1977 showing clumps of urate deposits. (methanamine silver $\times 30$ )

ducible effect in terminating an attack of acute gout (Sturge et al., 1977). This suggests that they may all have a common mode of action in gouty inflammation-perhaps the inhibition of prostaglandin synthetase-sufficient to block the whole process. But alternative pathways are available in rheumatoid disease so that control of inflammation is variable and partial.

We should also remember that some of our ideas about pathological processes in gout are conjectural and many questions remain to be answered. Why, for example, in some individuals can hyperuricaemia remain symptomless, without any evidence of urate deposition? Why again should urate deposits cause an inflammatory response at some times and not at others? The following case illustrates this point nicely.

A 73-year-old man had a history of recurrent gouty arthritis for eight years associated with a myeloproliferative disorder and renal insufficiency. By March 1977 he was suffering frequent attacks in

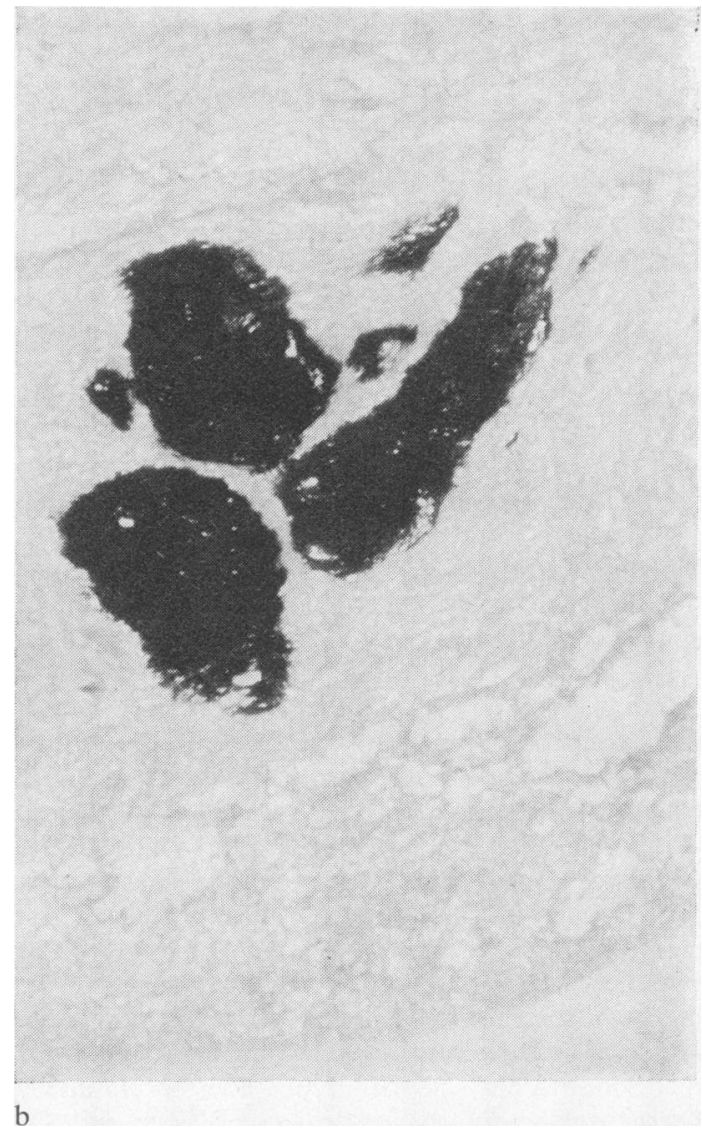

various joints, particularly the knees (Fig. 2). Joint fluid contained numerous urate crystals and arthroscopy showed abundant deposits of urate lying upon and within the synovial membrane (Fig. 3a). Histology of synovial membrane confirmed the presence of crystals and numerous small tophaceous deposits (Fig. 3b). Treatment with allopurinol lowered the serum urate from $800 \mu \mathrm{mol} / 1$ to $200 \mu \mathrm{mol} / 1 .(13.5 \mathrm{mg} / 100 \mathrm{ml}$ to $3.4 \mathrm{mg} / 100 \mathrm{ml})$. The acute attacks ceased almost at once, joint effusions resolved, and he became and remained free of symptoms. Arthroscopy was repeated in September 1977 on what was now a clinically normal knee. The same deposits of urate were seen upon the synovial membrane (Fig. 4a) and the histological appearance was unchanged from that of six months previously (Fig. 4b).

Why had acute inflammation subsided after the serum urate fell although the crystals were still seen apparently unchanged? Clinicians are familiar with the acute episodes of gout which are 


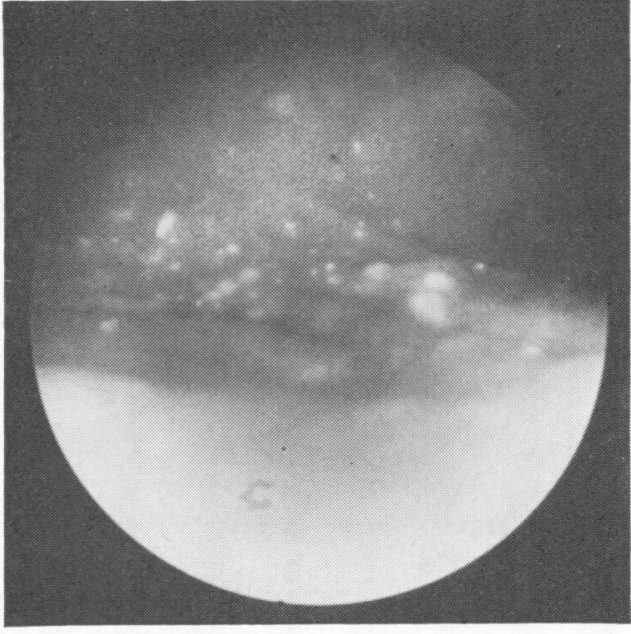

a

Fig. 4 Same patient as in Figs 2 and 3. (a) Arthroscopic appearance September 1977 showing little change. (b) Synovial biopsy September 1977 also showing little change from appearance in March (Fig. 3b).

occasionally seen for some time after the serum urate level has fallen. The question is not so much why they occur, since clearly deposits of urate do not vanish overnight, but rather why do they not occur more often?

Another problem of clinical importance is that of asymptomatic hyperuricaemia and its long-term effect on various organs, particularly the kidney (crystal-induced nephropathy) and cardiovascular system. These subjects, about which we remain very uncertain, are outside the scope of this paper. Indeed, our ability to treat acute gout and the underlying hyperuricaemia is considerably in advance of our understanding of many of the pathological processes involved.

\section{References}

Acheson, R. M., and Chan, Y. K. (1969). New Haven survey of joint diseases. The prediction of serum uric acid in a general population. Journal of Chronic Diseases, 21, 543-553.

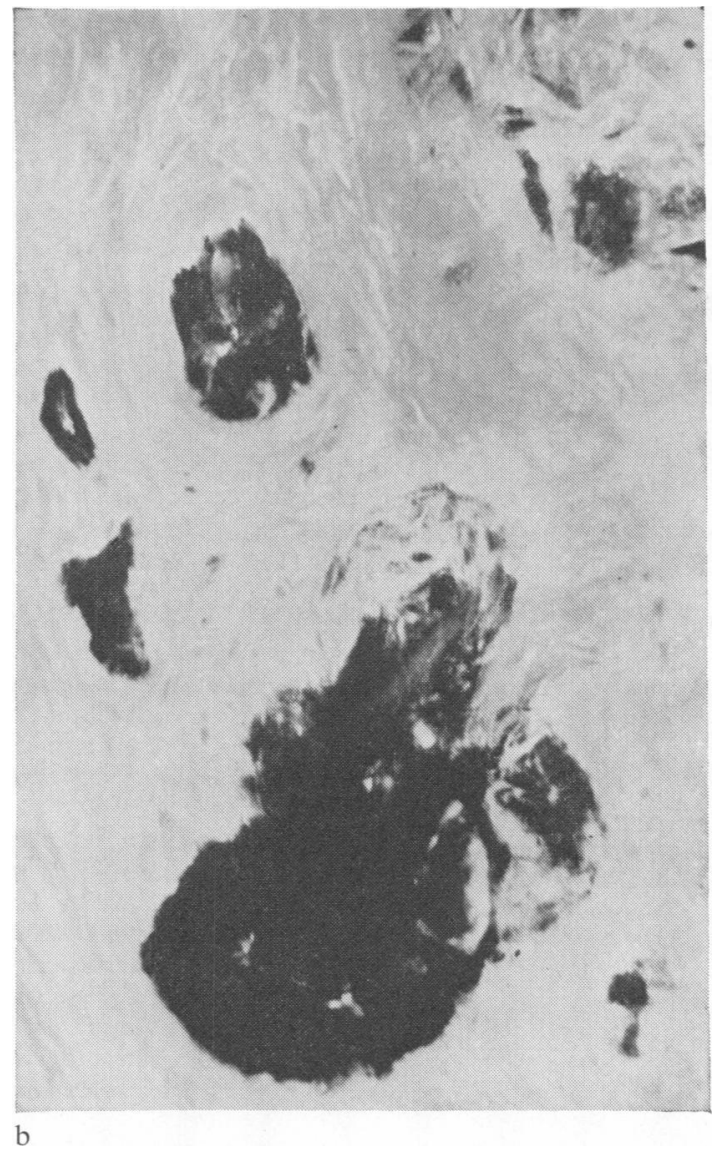

Agudelo, C. A., Schumacher, H. R., and Phelps, P. (1972). Effect of exercise on urate crystal-induced inflammation in canine joints. Arthritis and Rheumatism, 15, 609-616.

Campion, D. S., Olsen, R., Bluestone, R., and Klinenberg, J. R. (1975). Binding of urate by serum proteins. Arthritis and Rheumatism, 18, Supplement, 747-749.

Chang, Y-H., and Gralla, E. J. (1968). Suppression of urate crystal-induced canine joint inflammation by heterologous antipolymorphonuclear leukocyte serum. Arthritis and Rheumatism, 11, 145-150.

Faires, J. S., and McCarty, D. P., Jr. (1962). Acute synovitis in normal joints of man and dog produced by injections of microcrystalline sodium urate, calcium oxalate and corticosteroid esters. Arthritis and Rheumatism, 5, 295-296.

Farber, S. J., Cohen, G. L., and Kastor, J. A. (1962). The chemical and metabolic properties of acid mucopolysaccharides of renal papillae. Transactions of the Association of American Physicians, 75, 154-159.

Fessel, W. J. (1972). Hyperuricaemia in health and disease. Seminars in Arthritis and Rheumatism, 1, 275-299.

Fostiropoulos, K., Austen, K. F., and Bloch, K. J. 
(1965). Total hemolytic complement $\left(\mathrm{CH}_{50}\right)$ and a second component of complement activity in serum and synovial fluid. Arthritis and Rheumatism, 8, 219-232.

Garrod, A. B. (1859). The Nature and Treatment of Gout and Rheumatic Gout. Walton and Maberly, London.

Ginsberg. M. H., Kozin, F., O'Malley, M., and McCarty, D. J. (1977). Release of platelet constituents by monosodium urate crystals. Journal of Clinical Investigation, 60, 999-1007.

Hall, A. P., Barry, P. E., Dawber, T. R., and McNamara, P. M. (1967). Epidemiology of gout and hyperuricaemia. American Journal of Medicine, 42, 27-37.

Hasselbacher, P., and Schumacher, H. R., Jr., (1976). Localisation of immunoglobulin in gouty tophi by immunohistology and on the surface of monosodium urate cystals (MSU) by immune agglutination. Arthritis and Rheumatism, 19, 802 (abstract).

Katz, W. A. (1975). Deposition of urate crystals in gout. Arthritis and Rheumatism, 18, Supplement, 751-756.

Katz, W. A. (1977). Accelerated connective tissue metabolism in gout: effect of colichicine and diagnostic potential. Abstracts XIV International Congress Rheumatology, San Francisco.

Kellermeyer, R. W., and Naff, G. B. (1975). Chemical mediators of inflammation in acute gouty arthritis. Arthritis and Rheumatism, 18, 765-770.

Kippen, I., Klinenberg, J. R., Weinberger, A., and Wilcox, W. (1974). Factors affecting urate solubility in vitro. Annals of the Rheumatic Diseases, 33, 313-317.

Kjellstrand, C. M., Campbell, D. C. III, von Hartizseh, B., and Buselmeier, T. (1974). Hyperuricaemic acute renal failure. Archives of Internal Medicine, 133, 349-359.

Loeb, J. N. (1972). The influence of temperature on the solubility of monosodium urate. Arthritis and Rheumatism, 15, 189-192.

McCarty, D. J., and Hollander, J. L. (1961). Identification of urate crystals in gouty synovial fluid. Annals of Internal Medicine, 54, 452-460.

Naff, G. B., and Byers, P. H. (1973). Complement as a mediator of inflammation in acute gouty arthritis. I. Studies on the reaction between human serum complement and sodium urate crystals. Journal of Laboratory and Clinical Medicine, 81, 747-760.

Ortel, R. W., and Newcombe, D. S. (1974). Acute gouty arthritis and response to colchicine in the virtual absence of synovial-fluid leukocytes. New England Journal of Medicine, 290, 1363-1364.

Pekin, T. J., Jr., and Zvaifler, N. J. (1964). Haemolytic complement in synovial fluid. Journal of Clinical Investigation, 43, 1372-1382.

Phelps, P., and McCarty. D. J. (1966). Crystal-induced inflammation in canine joints. II. Importance of polymorphonuclear leukocytes. Journal of Experimental Medicine, 124, 115-126.

Phelps, D. (1970). Polymorphonuclear leukocyte motility in vitro: IV. Colchicine inhibition of chemotatic activity formation after phagocytosis of urate crystals. Arthritis and Rheumatism, 13, 1-9.

Rosenthale, M. E., Dervinis, A., Kassarich, J., and Singer, S. (1972). Prostaglandins and anti-inflammatory drugs in the dog knee joint. Journal of Pharmacy and
Pharmacology, 24, 149-150.

Scott, J. T. (1978). In Copeman's Textbook of the Rheumatic Diseases, 5th edition, edited by J. T. Scott, Chapter 26. Churchill Livingstone, Edinburgh and London.

Schumacher, H. R., and Phelps, P. (1971). Sequential changes in human polymorphonuclear leukocytes after urate crystal phagocytosis. Arthritis and Rheumatism, 14, 513-526.

Schumacher, H. R., Phelps, P., and Agudelo, C. A. (1974). Urate induced inflammation in dog joints: sequence of synovial changes. Journal of Rheumatology, 1, 102-113.

Seegmiller, J. E., Howell, R. R., and Malawista, S. E. (1962). The inflammatory reaction to sodium urate. Its possible relationship to the genesis of gouty arthritis. Journal of the American Medical Association, 180, 469-475.

Seegmiller, J. E., Laster, L., and Howell, R. R. (1963). Biochemistry of uric acid and its relation to gout. New England Journal of Medicine, 268, 716, 827.

Sicuteri, F. (1968). Sensitization of nociceptors by 5-hydroxtryptamine in men. In Pharmacology of Pain. (Proceedings of the 3rd International Pharmacology, Meeting, Vol. 9), edited by R. K. S. Lim, p. 70. Pergamon Press, Oxford.

Simkin, S. A. (1973). Local concentration of urate in the pathogenesis of gout. Lancet, 2, 1295-1298.

Snaith, M. L., and Scott, J. T. (1971). Uric acid clearance in patients with gout and normal subjects. Annals of the Rheumatic Diseases, 30, 285-289.

Sokoloff, L. (1957). The pathology of gout. Metabolism, 6, 230-243.

Spilberg, I. (1974). Urate crystal arthritis in animals lacking Hageman factor. Arthritis and Rheumatism, 17, 143-148.

Spilberg, I., and Osterland. C. K. (1970). Anti-inflammatory effect of the trypsin-kallikrein inhibitor in acute arthritis induced by urate crystals in rabbits. Journal of Laboratory and Clinical Medicine, 76, 472-479.

Stecher, R. M., Hersh, A. H., and Solomon, W. M. (1949). The heredity of gout and its relationship to familial hyperuricaemia. Annals of Internal Medicine, 31, 595-614.

Sturge, R. A., Scott, J. T., Kennedy, A. C., Hart, D. P., and Watson Buchanan, W. (1977). Serum uric acid in England and Scotland. Annals of the Rheumatic Diseases, 36, 420-427.

Sturge, R. A., Scott. J. T., Hamilton, E. B. D., Liyanage, S. P., Dixon, A. StJ., Davies, J., and Engler, C. (1977). Multicentre trial of naproxen and phenylbutazone in acute gout. Annals of the Rheumatic Diseases, 36, 80-82.

Talbott, J. H. (1959). Gout and blood dyscrasis. Medicine (Baltimore), 38, 173-205.

Townes, A. S., and Sowa, J. M. (1970). Complement in synovial fluid. Johns Hopkins Medical Journal, 127, 23-37.

Van Arman, C. G., Carlson, R. P., Kling, P. J., Allen, D. J., and Bondi, J. V. (1974). Experimental gouty synovitis caused by bacterial endotoxin absorbed on to 
urate crystals. Arthritis and Rheumatism, 17, 439-449.

Wyngaarden, J. B., and Kelley, W. N. (1976). Gout and Hyperuricaemia. Grune and Stratton, New York.

Wallingford, W.R., and McCarty. D.J. (1971). Differential membranolytic effects of microcrystalline sodium urate and calcium pyrophosphate dihydrate. Journal of Experimental Medicine, 133, 100-112.
Weissmann, G., and Rita, G. (1972). Molecular basis of gouty inflammation: interaction of monosodium urate crystals with lysosomes and liposomes. Nature (New Biology), 240, 167-172.

$\mathrm{Yu}, \mathrm{T}$. F., and Gutman, A. B. (1953). Ultrafiltrability of plasma urate in man. Proceedings of the Society for Experimental Biology and Medicine, 84, 21-24. 